\section{RESUTT OF THE CASE OF}

\section{INGUINAL ANEURISM}

AT THE BRISTOL INFIRMARY, IN WHICH THE EXTERNAL ILIAC WAS TIED BY Richard Smith, Esq., the Senior Surg.*

\section{To the Editor of 'THE LANCET.}

SrR,-I have delayed addressing you respecting the case of inguinal aneurism, in which $I$ placed a ligature upon the external iliac on the 21st of May, wishing previously to feel quite assured of what would be the result of the operation. Two months having now elapsed, I presume that all is quite safe.

i have the satisfaction to inform you, that Ricketts had not one unpleasant symptom from the moment when he was carried to bed to the present time. His gloomy despair soon left him, and was succeeded by a confident and cheering hope in the prospect newly opened to his view. In about a week the wound was entirely closed, with the exception only of the part situated in the course of the ligature. From this period there was discharged during each day about an ounce of good pus. On the 30th day after the operation the ligature was found coiled up in the dressing. In a short time after this the discharge entirely ceased, the wound healed, and the man walked home without any difficulty.

Ten days ago Ricketts returned to the infirmary, in order that I might examine the part where the aneurismal swelling had been situated. I found that the tumour had disappeared from the surface, and the remains of it were only distinguishable by the touch, as a circumscribed lump under the integuments. There is not the slightest pulsation, and moderate pressure gives no uneasiness. The limb is perfectly natural, and he has the free use of it. In fact, with the exception of the scar upon the abdomen, there is no visible trace either of the aneurism or the operation. He said that "he was quite well, and had nothing the matter."

It has been rather a subject of surprise to me, a very agreeable one of course, that there should have been so entire an absence of constitutional and local disturb. ance, considering the interruption of the circulation in so large a vessel, and the unavoidable injuries necessarily inflicted by the scalpel and the handling.

The operation has been already so many times performed with success, and its pro-

* See Lancer, present rolume, page 387. priety so thoroughly established, that I should not have considered it needful to trouble you, but the commencement of the case having already found a place in your pages, I thought that the sequel ought to appear also in the same channel.

I am, Sir, yours very truly,

RichaRd SMiTh,

22nd July, 1833.

Senior-Surgeon, Bristol Infirmary.

VIEW OF

BARON ALIBERT'S CLASSIFICATION

or

\section{DISEASES OF THE SKIN.}

By John Paget, M.D.

(Concluded from page 527.)

GROUP VIIT.-STRUMA.

These are chronic affections of the skin, of various forms, generally with glandular swellings, which are apt to terminate in nlcerations, and are little affected by any known remedy. The strumce are undoubtedly hereditary, and seem to depend on a certain constitutional diathesis, the nature of which is little mderstood, but which may show itself in every tissue of the body, and would seem to consist essentially in a disposition to deposit tuberculous matter.

Genus 1st, Scrofura.-An affection which declares itself on one or more parts of the integument by the hypertrophy, induration, and prominence of the lymphatic glands, by the formation of spots, scales, tubercles, and pustules, followed by ulcerations, incrustations, hypertrophies, cellular vegetations of the skin, \&c. These tumours or swellings, the result of a morbid change, as yet but little understood, have their special seat in the glands, as the parotid, submaxillary, sublingual, cervical, \&c. The genus, taken collectively, presents itself under two opposite aspects; in the one, the patient has a fiorid colour, and the external appearance of a healthy and robust constitution; in the other, the face is thin and pale, the eyes dull, and the whole appearance that of wasting and decay.

Species a, S. vulgaris vel sporadica; $b, S$. endemica.

Genus 2nd, Farcimen. (Farcy or Glanders.) - An affection peculiar to domestic animals, especially characterized 